\title{
Characterization of Serratia odorifera, S. fonticola and S. ficaria by the Electrophoretic Patterns of their Esterases
}

\author{
By Pн. GOULLET \\ Laboratoire de Microbiologie, Faculté de Médecine Xavier-Bichat (Université Paris VII), \\ 16 rue Henri Huchard, 75018 Paris, France
}

(Received 10 February 1981; revised 12 April 1981)

Esterases of 15 strains of Serratia odorifera, 14 strains of $S$. fonticola and 13 strains of $S$. ficaria were resolved by horizontal electrophoresis in polyacrylamide-agarose gel. Esterase bands were defined by their range of activity towards several synthetic substrates and their sensitivity or resistance to di-isopropyl fluorophosphate. Serratia odorifera strains showed three to five major esterase bands and three minor bands. Serratia fonticola strains showed three or four major bands and one minor band. Serratia ficaria strains showed three to five major bands and one minor band. The comparative distribution of bands revealed that these three newly described species could be distinguished by the electrophoretic patterns of their esterases. Congruence was found between biotypes 1 and 2 of $S$. odorifera and electrophoretic patterns. These species-specific patterns were different from those of $S$. marcescens, $S$. liquefaciens, $S$. plymuthica and $S$. marinorubra previously characterized.

\section{INTRODUCTION}

Serratia marcescens, $S$. liquefaciens, $S$. plymuthica and $S$. marinorubra have been characterized previously by the distinct electrophoretic patterns of their esterases (Goullet, 1978). The purpose of this study was to characterize three newly described species of Serratia - S. odorifera, biotypes 1 and 2 (Grimont et al., 1978), S. fonticola (Gavini et al., 1979 ) and $S$. ficaria (Grimont et al., 1979) - by the same procedure.

\section{METHODS}

The names and sources of the test strains are given in Table 1. Growth conditions, preparation of extracts, protein estimation, heat inactivation, inhibition by di-isopropyl fluorophosphate (DFP), horizontal slab electrophoresis in polyacrylamide-agarose gel, esterase staining and estimation of electrophoretic mobility $\left(M_{F}\right.$ value) were all as described previously (Goullet, 1980).

\section{RESULTS}

Esterase bands migrating towards the anode and varying in sharpness and colour intensity were found for each of the $\mathbf{4 2}$ strains. Esterase banding patterns were sufficiently distinctive and reproducible to identify the species, and eventually the biotype, of each strain analysed. For each species, major esterase bands $\left(E_{1}\right.$ to $\left.E_{s}\right)$ and minor bands $\left(m_{1}\right.$ to $\left.m_{3}\right)$ were designated in order of decreasing electrophoretic mobility.

\section{Serratia odorifera}

Strains of $S$. odorifera showed two sets of esterase bands (Fig. $1 a$ ). One set (bands $\mathrm{E}_{1}, \mathrm{E}_{2}$, $m_{1}, m_{2}$ and $\left.m_{3}\right)$ resisted DFP $\left(10^{-3} M\right.$ ), whereas the other set (bands $E_{3}, E_{4}$ and $E_{5}$ ) was sensitive to this agent. Band $E_{1}$ hydrolysed $\beta$-naphthyl acetate and, to a lesser extent, 
Table 1. Strains of Serratia examined

\begin{tabular}{|c|c|c|}
\hline Code & Organism & Strain* \\
\hline 1 & S. odorifera & Grimont $38(a)$ \\
\hline 2 & S. odorifera & Grimont $1073(a)$ \\
\hline 3 & S. odorifera & Richard $35.72(b)$ \\
\hline 4 & S. odorifera & Richard $2.73(b)$ \\
\hline 5 & S. odorifera & Richard $17.74(b)$ \\
\hline 6 & S. odorifera & Richard $12.76(b)$ \\
\hline 7 & S. odorifera & Richard $11.77(b)$ \\
\hline 8 & S. odorifera & Richard $12.77(b)$ \\
\hline 9 & S. odorifera & CDC $4409.66(a)$ \\
\hline 10 & S. odorifera & CDC $292.74(a)$ \\
\hline 11 & S. odorifera & CDC $2861.74(a)$ \\
\hline 12 & S. odorifera & CDC $3472.74(a)$ \\
\hline 13 & S. odorifera & CDC $1396.75(a)$ \\
\hline 14 & S. odorifera & CDC $3567.75(a)$ \\
\hline 15 & S. odorifera & CDC $1517.76(a)$ \\
\hline 16 & S. fonticola & CUETM $77.153(\mathrm{c})$ \\
\hline 17 & S. fonticola & CUETM $77.168(c)$ \\
\hline 18 & S. fonticola & CUETM $78.7(c)$ \\
\hline 19 & S. fonticola & CUETM $78.9(c)$ \\
\hline 20 & S. fonticola & CUETM $78.10(c)$ \\
\hline 21 & S. fonticola & CUETM $78.11(c)$ \\
\hline 22 & S. fonticola & CUETM $78.14(c)$ \\
\hline 23 & S. fonticola & CUETM $78.20(c)$ \\
\hline 24 & S. fonticola & CUETM $78.22(c)$ \\
\hline 25 & S. fonticola & CUETM $78.26(c)$ \\
\hline 26 & S. fonticola & CUETM $78.28(c)$ \\
\hline 27 & S. fonticola & CUETM $78.43(c)$ \\
\hline 28 & S. fonticola & CUETM $78.45(c)$ \\
\hline 29 & S. fonticola & CUETM 78.49 (c) \\
\hline 30 & S. ficaria & Grimont $2602(a)$ \\
\hline 31 & S. ficaria & Grimont $4024(a)$ \\
\hline 32 & S. ficaria & Grimont $4025(a)$ \\
\hline 33 & S. ficaria & Grimont $4026(a)$ \\
\hline 34 & S. ficaria & Grimont $4027(a)$ \\
\hline 35 & S. ficaria & Grimont $4028(a)$ \\
\hline 36 & S. ficaria & Grimont $4029(a)$ \\
\hline 37 & S. ficaria & Grimont $4030(a)$ \\
\hline 38 & S. ficaria & Grimont $4033(a)$ \\
\hline 39 & S. ficaria & Grimont $4034(a)$ \\
\hline 40 & S. ficaria & Grimont $4037(a)$ \\
\hline 41 & S. ficaria & Grimont $4038(a)$ \\
\hline 42 & S. ficaria & Grimont $4039(a)$ \\
\hline
\end{tabular}

Biotype ${ }^{-}$Source and other strain designation $\neq$

1 Cultivated mushroom, Bordeaux, France

I Sputum, Bordeaux, France; ICPB 3995, holotype

1 Faeces, Toulon, France

1 Mussel, Saint-Etienne, France

1 Blood, Lyon, France

1 Pus, Paris, France

1 Sputum, Paris, France

1 Pleura pus, Santander, Spain

2 Lung, Connecticut, U.S.A.

2 Blood, California, U.S.A.

2 Tracheal secretion, California, U.S.A.

2 Blood, Massachusetts, U.S.A.

2 Bronchial washing. Vermont. U.S.A.

2 Urine, New Jersey, U.S.A.

2 Tracheal exudate, Pennsylvania, U.S.A.

Drinking water, NF

Drinking water, NF

Surface water, NF

Drinking water, NF

Unpolluted soils, NF

Drinking water, NF

Unpolluted soils, NF

Drinking water, NF

Sewage, NF

Drinking water, NF

Drinking water, NF

Drinking water, NF

Drinking water, NF

Drinking water, NF

Black ant, Bordeaux, France (July 1976)

Calimyrna fig. Winters, California, U.S.A.

(September 1977); ICPB 4050, CIP 79.23,

ATCC 33105, holotype

Caprifig, Winters, California, U.S.A.

(September 1977); ICPB 4051, ATCC 33106

Caprifig, Winters, California, U.S.A.

(September 1977); ICPB 4052

Caprifig, Winters, California, U.S.A.

(September 1977); ICPB 4053

Caprifig, Fresno, California, U.S.A. (October 1977); ICPB 4054

Caprifig, Fresno, California, U.S.A. (October 1977); ICPB 4055

Blastophaga psenes, Fresno, California, U.S.A. (October 1977); ICPB 4056

Blastophaga psenes, Fresno, California. U.S.A. (October 1977); ICPB 4058

Calimyrna fig, Winters, California, U.S.A.

(September 1977); ICPB 4059

Blastophaga psenes in a caprifig, Gammarth, Tunisia (June 1978)

Caprifig, Gammarth, Tunisia (June 1978)

Fig, Sfax, Tunisia (June 1978)

* (a) Strain provided by Dr P. A. D. Grimont. Service des Entérobactéries (Professeur L. Le Minor), Institut Pasteur. Paris, France: $(b)$ strain provided by Dr C. Richard, Service des Entérobactéries, Institut Pasteur; (c) strain provided by Dr F. Gavini, Unité d'Ecotoxicologie Microbienne (Professeur H. Leclerc), Domainde du CERTIA, 59650 Villeneuve a'Ascq, France. CDC, Center for Disease Control. Atlanta, U.S.A.: CUETM, Collection de l'Unité d'Ecotoxicologie Microbienne.

+ According to Grimont et al. (1978).

$\ddagger$ NF, strain from the North of France; ICPB, International Collection of Phytopathogenic Bacteria, Davis, California, U.S.A.; CIP, Collection de l'Institut Pasteur, Paris, France; ATCC, American Type Culture Collection. Rockville. U.S.A. 


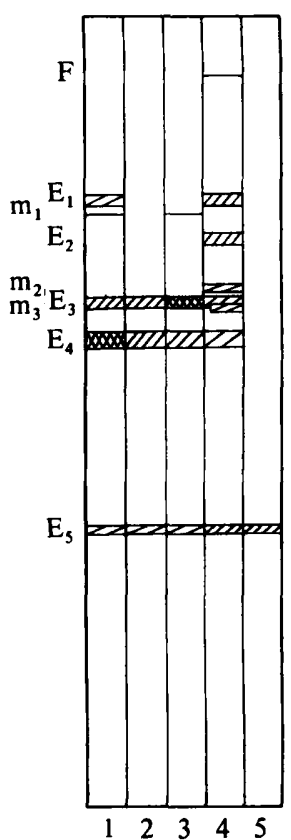

(a)
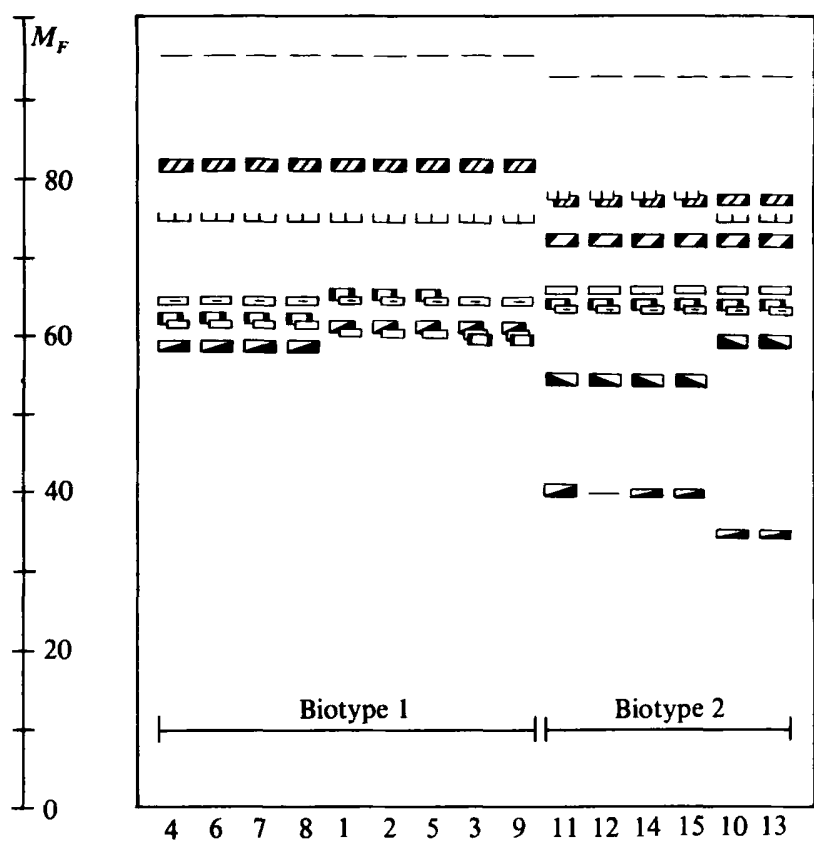

(b)

Fig. 1. Serratia odorifera. (a) Diagrammatic representation of mobility and activity of esterase bands (strain 10). Horizontal slab polyacrylamide-agarose gel electrophoresis was performed using $7 \%(w / v)$ acrylamide and discontinuous Tris/glycine buffer, $\mathrm{pH}$ 8.7. Substrates used were: $1, \alpha$-naphthyl acetate; 2, $\alpha$-naphthyl butyrate; 3 , indoxyl acetate; $4, \beta$-naphthyl acetate; 5 , $\beta$-naphthyl butyrate. Relative intensity of staining: $>\square Z I D>\square Z \square>\square Z$. (b) Esterase patterns of 15 strains (numbered as in Table 1) arranged according to biotype. $Z, \mathrm{E}_{1}$ band; $\square, \mathrm{E}_{2}$ band; $\square, \mathrm{E}_{3}$ band; $\square, \mathrm{E}_{4}$ band; $\square, \mathrm{E}_{5}$ band; $L \perp, \mathrm{m}_{1}$ band; $\square, \mathrm{m}_{2}$ band; $\square, \mathrm{m}_{3}$ band; $\longrightarrow$ F band. The $M_{F}$ values were used only comparatively.

$\alpha$-naphthyl acetate. Band $\mathrm{m}_{1}$ was faint and detected by indoxyl acetate and $\alpha$-naphthyl acetate. Bands $E_{2}, m_{2}$ and $m_{3}$ were stained by $\beta$-naphthyl acetate. Band $m_{3}$ was resistant to heat $\left(10 \mathrm{~min}\right.$ at $\left.60^{\circ} \mathrm{C}\right)$. Band $\mathrm{E}_{3}$ hydrolysed indoxyl acetate, $\alpha$-naphthyl acetate and $\alpha$-naphthyl butyrate, and reacted slightly with $\beta$-naphthyl acetate. Band $E_{4}$ hydrolysed $\alpha$-naphthyl acetate and, to a lesser extent, $\alpha$-naphthyl butyrate, indoxyl acetate and $\beta$-naphthyl acetate. Band $E_{5}$ hydrolysed $\beta$-naphthyl esters and, to a lesser extent, the other substrates. This band was faint in strain 12. Finally, one fast moving band $(F)$ was detected by $\beta$-naphthyl acetate. Figure $1(b)$ shows the electrophoretic distribution of esterases in the 15 strains. All strains produced bands $E_{1}, E_{3}, E_{5}, m_{1}, m_{2}, m_{3}$ and $F$. Differences in mobilities between bands were often small and two or three bands overlapped in some strains: bands $E_{1}$ and $m_{1}$ for strains $11,12,14$ and 15 ; bands $E_{3}$ and $m_{2}$ for strains $4,6,7$ and 8 ; bands $E_{3}$ and $m_{3}$ for strains $1,2,5,10,11,12,13,14$ and 15 ; bands $E_{5}$ and $m_{2}$ for strains 1,2 and 5; bands $E_{3}, E_{3}$ and $m_{2}$ for strains 3 and 9 . Separation and characterization of bands were then achieved by using 6 or $8 \%(w / v)$ acrylamide (instead of $7 \%$ ) and by noting differences in heat inactivation or in DFP inhibition. Distinct electrophoretic distributions were observed according to the biotypes. Bands $E_{1}, E_{3}$ and $F$ showed differences in mobility between the two biotypes, whereas bands $E_{2}$ and $E_{4}$ were detected in biotype 2 only. Strains 10 and 13 of biotype 2 differed from other strains of this biotype in the mobility of bands $m_{1}, E_{4}$ and $E_{s}$.

\section{Serratia fonticola}

Strains of this species produced four or five esterase bands that hydrolysed $\beta$-naphthyl acetate but differed in activity towards other substrates (Fig. 2). Bands $m_{1}$ and $E_{2}$ hydrolysed 


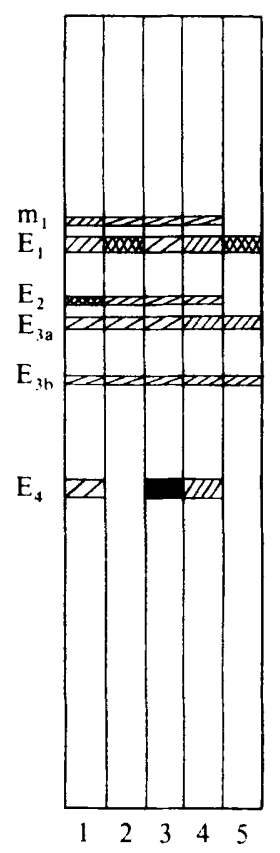

(a)

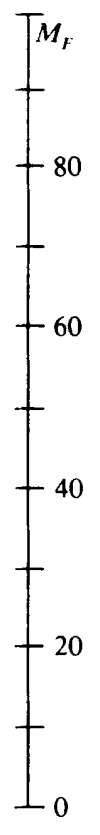

$($ b)

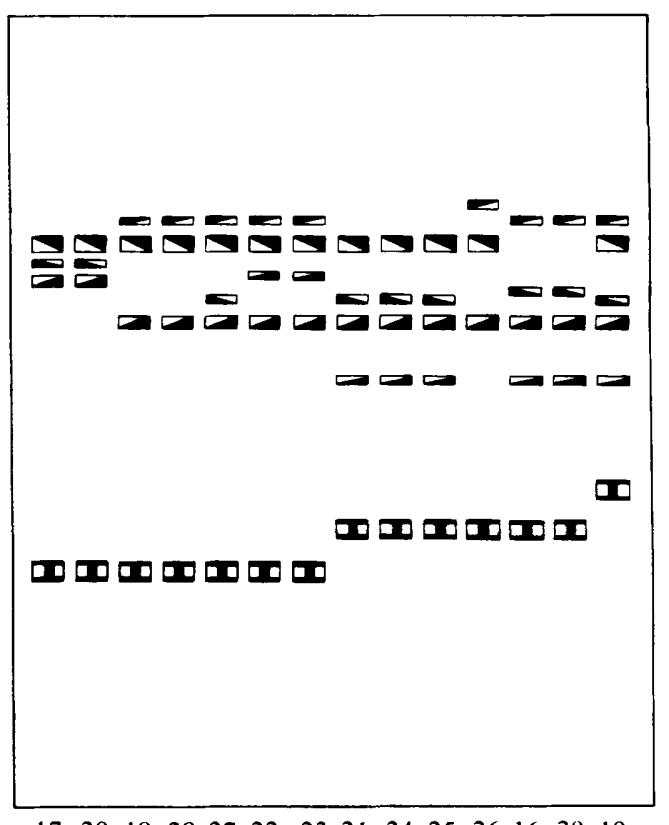

Fig. 2. Serratia fonticola. (a) Diagrammatic representation of mobility and activity of esterase bands (strain 19). (b) Esterase patterns of 14 strains. Experimental conditions and relative intensity of staining as in legend to Fig. 1. $\square, E_{1}$ band; $\square, E_{2}$ band; $\square, E_{3}$ band; $\square-E_{4}$ band; $\square$, $\mathrm{m}_{1}$ band.

$\alpha$-naphthyl acetate and to a lesser degree $\alpha$-naphthyl butyrate, indoxyl acetate and $\beta$-naphthyl acetate, whereas band $\mathrm{E}_{1}$ hydrolysed $\alpha$ - and $\beta$-naphthyl butyrates and, to a lesser extent, $\alpha$ and $\beta$-naphthyl acetates. Band $\mathrm{E}_{3}$ was active towards $\beta$-naphthyl esters and reacted slightly with other substrates; it showed some residual activity after incubation for $10 \mathrm{~min}$ at $60{ }^{\circ} \mathrm{C}$. In some strains $(16,19,21,22,23,24,25$ and 29) this esterase showed two electrophoretically distinct components: $E_{3 a}$ and $E_{3 b}$. Bands $m_{1}, E_{1}, E_{2}$ and $E_{3}$ were inhibited by $10^{-3} M-D F P$. Band $E_{4}$ reacted strongly with indoxyl acetate, moderately with $\beta$-naphthyl acetate and weakly with $\alpha$-naphthyl acetate; it was a prominent band consisting of several diffuse sub-bands and resisted $10^{-3} \mathrm{M}$-DFP. Only bands $\mathrm{E}_{3}$ and $\mathrm{E}_{4}$ were observed in all strains. Band $E_{1}$ showed the same mobility among the strains but was not recovered in strains 16 and 29 . Band $\mathrm{F}$ was not detected.

Significant heterogeneity in the number and mobility of esterase bands was observed within this species. However, species identification was possible by combination of bands $E_{1}, E_{3}$ and $E_{4}$ for most strains and by combination of bands $m_{1}, E_{2}, E_{3}$ and $E_{4}$ for strains 16 and 29.

\section{Serratia ficaria}

Between five and seven esterase bands were recovered from $S$. ficaria strains (Fig. 3). Band $E_{1}$ was stained by $\alpha$ - and $\beta$-naphthyl acetates. In most of the strains this band showed two electrophoretically distinct components: $E_{1 a}$ and $E_{1 b}$. Band $m_{1}$ was faint and detected by indoxyl acetate and $\alpha$-naphthyl acetate as was the corresponding band of $S$. odorifera. Band $\mathrm{E}_{2}$ hydrolysed $\alpha$-naphthyl acetate. Band $\mathrm{E}_{3}$ hydrolysed $\beta$-naphthyl acetate and was resistant to heat. Band $E_{4}$ reacted strongly with indoxyl acetate, moderately with $\beta$-naphthyl acetate and weakly with $\alpha$-naphthyl acetate; it was a prominent band composed of several sub-bands distinctly separated from each other. Band $\mathrm{E}_{s}$ hydrolysed $\beta$-naphthyl esters. Band $\mathrm{F}$, detected 


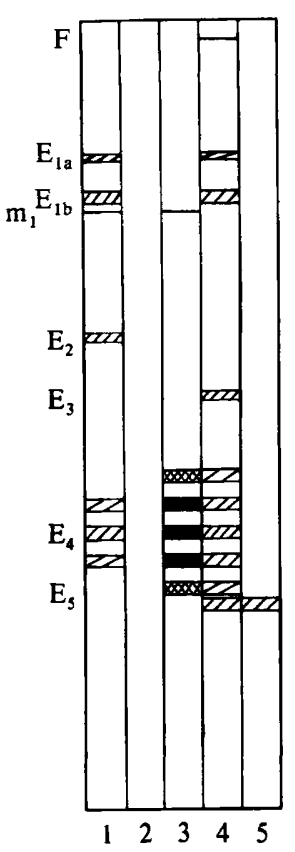

(a)

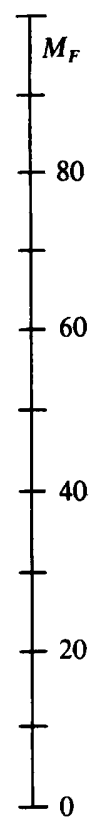

Fig. 3. Serratia ficaria. (a) Diagrammatic representation of mobility and activity of esterase bands (strain 34). (b) Esterase patterns of 13 strains. Experimental conditions and relative intensity of staining as in legend to Fig. 1. $\square, \mathrm{E}_{1}$ band; $\square, \mathrm{E}_{2}$ band; $\square, \mathrm{E}_{3}$ band; $\square \square, \mathrm{E}_{4}$ band; $\square$, $E_{5}$ band; $L \perp \perp, m_{1}$ band; —,$F$ band.

by $\beta$-naphthyl acetate, was electrophoretically distinct $\left(M_{F} \approx 97\right)$ from the corresponding band of $S$. odorifera biotype $1\left(M_{F} \approx 95\right)$ and biotype $2\left(M_{F} \approx 92\right)$. Bands $\mathrm{E}_{2}, \mathrm{E}_{5}$ and $\mathrm{F}$ were completely inhibited by treatment with $10^{-3} \mathrm{M}$-DFP, whereas bands $\mathrm{E}_{1}, \mathrm{E}_{3}, \mathrm{E}_{4}$ and $\mathrm{m}_{1}$ remained active. Bands $\mathrm{E}_{1}, \mathrm{~m}_{1}, \mathrm{E}_{4}$ and $\mathrm{E}_{5}$ were observed in all strains (Fig. $3 b$ ). The electrophoretic mobility of bands $\mathrm{F}\left(M_{F} \approx 97\right), \mathrm{m}_{1}\left(M_{F} \approx 76\right)$ and $E_{3}\left(M_{F} \approx 26\right)$ showed no 'between-strains' variation.

Heterogeneity in esterase patterns was also observed within this species. On the basis of variation in the number and mobility of esterase bands, three subclusters of strains could be distinguished. Subcluster 1 (strains $31,32,34,36$ and 39) contained band $E_{3}$, whereas subclusters 2 and 3 lacked this band. Subcluster 2 (strains 30, 33, 35, 37 and 38) differed from subcluster 3 (strains 40,41 and 42 ) in the mobilities of bands $E_{1}$ and $E_{4}$.

\section{DISCUSSION}

Electrophoretic analysis has demonstrated that $S$. odorifera, $S$. fonticola and $S$. ficaria may be characterized by the distinct banding patterns of their esterases and that biotypes 1 and 2 of $S$. odorifera can be identified by differences in distribution of their esterases (Fig. 1, 2, 3; Table 2). The specific patterns of these species were clearly distinguishable from those of $S$. marcescens, $S$. liquefaciens, $S$. plymuthica and $S$. marinorubra (Goullet, 1978). These findings correlate well with DNA homology studies which showed that the new Serratia species constitute three hybridization groups clearly distinct from the other Serratia species (Grimont et al., 1978, 1979; Gavini et al., 1979). Recognition of the two biotypes of $S$. odorifera by differences in esterase patterns supports the subdivision based on biochemical characteristics and reflects the genetic divergence observed within this species (Grimont et al., 1978). 
Table 2. $M_{F}$ values of esterase bands of $S$. odorifera (biotypes 1 and 2 ), S. fonticola and S. ficaria

Mean $M_{F}$ values are given together with the standard deviation.

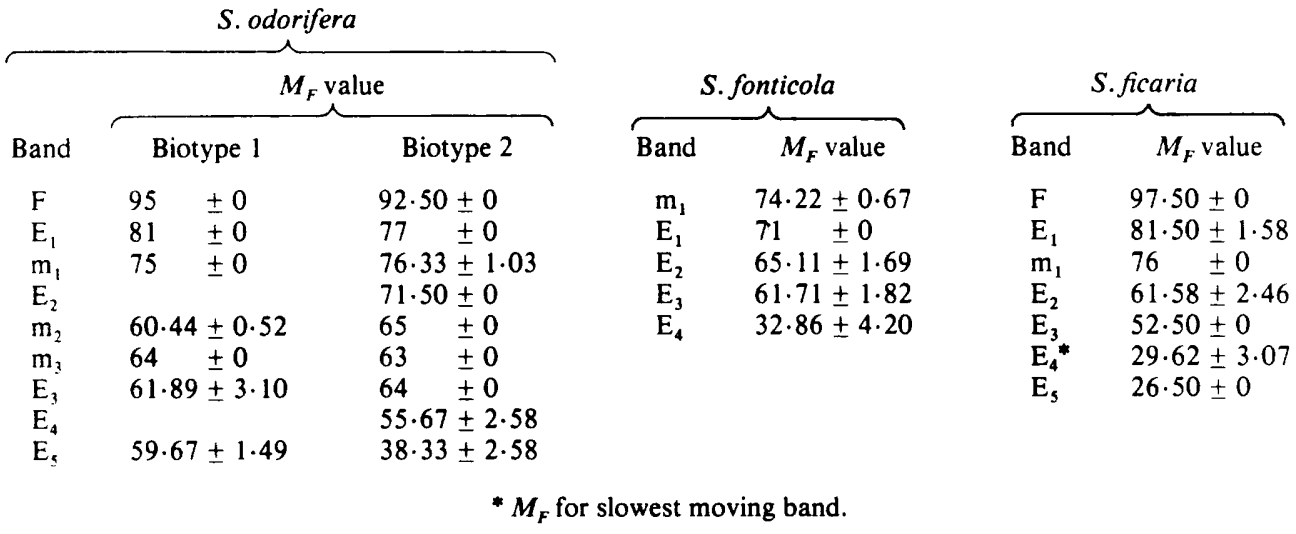

However, similarities appeared in the range of hydrolysing activities of several esterase bands produced by Serratia species. Band $\mathrm{E}_{4}$ of $S$. odorifera (biotype 2) and band $\mathrm{E}_{2}$ of $S$. fonticola showed the same range of hydrolysing activity as bands $\mathrm{E}_{1}$ of $S$. marcescens, $S$. liquefaciens, $S$. plymuthica and $S$. marinorubra. Bands $\mathrm{E}_{5}$ of $S$. odorifera and $\mathrm{E}_{3}$ of $S$. fonticola resembled band $E_{3}$ of these four last species in their preferential hydrolysis of $\beta$-naphthyl esters. Bands $\mathrm{E}_{4}$ of $S$. fonticola and of $S$. ficaria were practically identical to the corresponding bands of $S$. marcescens, $S$. liquefaciens and $S$. plymuthica with respect to their strong activity towards indoxyl acetate and their resistance to inhibition by DFP. Band $E_{5}$ of $S$. ficaria reacted with $\beta$-naphthyl acetate and $\beta$-naphthyl butyrate as did the corresponding bands of $S$. marcescens, $S$. liquefaciens and $S$. plymuthica. These similarities between some esterase bands are in agreement with the 25 to 55\% DNA-DNA relatedness observed between Serratia species (Grimont et al., 1978, 1979; Gavini et al., 1979; Steigerwalt et al., 1976). As observed for the Serratia species analysed previously, S. odorifera, S. fonticola and $S$. ficaria showed intraspecies variations in the number and mobilities of esterase bands. This heterogeneity appeared even for $S$. ficaria strains which constitute a homologous taxon with $90 \%$ DNA-DNA relatedness (Grimont et al., 1979).

The present work supports the phenotypic and genotypic individuality of the newly described species of Serratia and shows that esterases give discriminative and reliable information for both specific and subspecific differentiation.

The author thanks Drs P. A. D. Grimont, F. Gavini and C. Richard for strains, and Madame Colette Gaillard and Mademoiselle Catherine Lamesch for technical assistance. This work was supported by grants from the Université de Paris VII and from the Institut National de la Santé et de la Recherche Médicale (no. 78.1.136.1).

\section{REFERENCES}

Gavini, F., Ferragut, C., Izard, D., Trinel, P. A., LeClerc, H., Lefebvre, H. \& Mossel, D. A. A. (1979). Serratia fonticola, a new species from water. International Journal of Systematic Bacteriology 29, 92-101.

Goullet, PH. (1978). Characterization of Serratia marcescens, $S$. liquefaciens, $S$. plymuthica and $S$. marinorubra by the electrophoretic patterns of their esterases. Journal of General Microbiology 108, 275-281.

Goullet, PH. (1980). Distinctive electrophoretic patterns of esterases from Klebsiella pneumoniae, $K$. oxytoca, Enterobacter aerogenes and E. gergoviae. Journal of General Microbiology 117, 483491.

Grimont, P. A. D., Grimont, F., Richard, C., Davis, B. R., Steigerwalt, A. G. \& Brenner, D. J. (1978). Deoxyribonucleic acid relatedness between Serratia plymuthica and other Serratia species, with a description of Serratia odorifera sp. nov. (type strain: ICPB 3995). International Journäl of Systematic Bacteriology 28, 453-463. 
Grimont, P. A. D., Grimont, F. \& Starr, M. P. Steigerwalt, A. G., Fanning Richard, G., Fife(1979). Serratia ficaria sp. nov., a bacterial species associated with smyrna figs and the fig wasp blastophaga psenes. Current Microbiology 2, 277282.

ASBURY, M. A. \& BRENNER, D. J. (1976). DNA relatedness among species of Enterobacter and Serratia. Canadian Journal of Microbiology 22, 121-137. 